\title{
A PARTICIPAÇÃO EM PESQUISAS COM METODOLOGIAS PARTICIPATIVAS: REFLEXÃO SOBRE EXPERIÊNCIAS
}

\section{Participation in Researches with Participative Methodologies: Reflections about Experiences}

\author{
José Renato Gatto Júnior \\ Escola de Enfermagem de Ribeirão Preto - Universidade de São Paulo - São Paulo (SP) - Brasil \\ Leandra Andréia de Sousa \\ Escola de Enfermagem de Ribeirão Preto - Universidade de São Paulo - São Paulo (SP) - Brasil
}

\section{Sébastien Pesce}

Université François Rabelais de Tours - Tours - France

Cinira Magali Fortuna

Escola de Enfermagem de Ribeirão Preto - Universidade de São Paulo - São Paulo (SP) - Brasil

\section{RESUMO}

Objetivo: Refletir acerca da participação, tomando como base algumas experiências de pesquisa com metodologia participativa. Métodos: As etapas para a composição desta reflexão foram: 1-) seleção de características significativas na experiência/ vivência durante pesquisas com metodologias participativas 2-) apresentação e discussão das características selecionadas; e 3-) sintetização de apontamentos relevantes. Foram consideradas as seguintes características significativas: a questão da participação enquanto processo (níveis de participação ao longo do processo investigativo); a flexibilidade no uso de técnicas de coleta de dados: ponto-chave na construção do processo participativo; os ciclos: novos participantes, novas formas de participação. Resultados: Com base nessas considerações, no processo de participação, ao longo do decorrer da pesquisa é esperado que a participação ou nível de participação varie progressivamente (número de participantes e intensidade de participação - o que provoca submissões de emendas em comitês de ética). Enquanto alguns defendem a flexibilidade como um critério de rigor nas pesquisas participantes, outros referem que a abordagem flexível ainda é considerada como de menor rigor científico. Conclusão: A participação enquanto um processo em construção, usando-se da flexibilidade e outros dispositivos provocadores de transformação, é vista como uma potente ferramenta a ser intensamente desenvolvida durante uma investigação com metodologia participativa.

Descritores: Participação cidadã; Pesquisa qualitativa; Pesquisa Participativa baseada na Comunidade.

\section{ABSTRACT}

Objective: Thus, this article seeks to provoke new reflections about participation, based on some research experiences with participatory methodology. Methods: The steps for the composition of this reflection were: 1-) selection of significant characteristics from the experiences during research with participatory methodologies 2-) presentation and discussion of the selected characteristics; and 3-) synthesizing relevant annotations. The following significant characteristics were considered: the question of participation as a process (levels of participation throughout the investigative process); flexibility in the use of data collection techniques: a key point in the construction of the participatory process; the cycles: new participants, new forms of participation. Results: Based on these considerations, in the process of participation, the participation or level of participation is expected to progressively vary (number of participants and intensity of participation - which leads to submissions of amendments in ethics committees) throughout the course of the research. While some advocate flexibility as a rigor criterion in participatory research, others argue that the flexible approach is still considered to be of less scientific rigor. Conclusion: Participation as a process under construction, using flexibility and other transformative devices, is seen as a powerful tool to be intensively developed during a participatory methodology research.

Descriptors: Citizen Participation; Qualitative Research; Community-based Participatory Research. 


\section{INTRODUÇÃO}

A noção de "participação" é largamente convocada para evocar as modalidades de implicação dos atores do cenário ou dos cidadãos nos dispositivos de pesquisa e, de forma geral, da colaboração entre pesquisadores, profissionais, usuários etc. A noção de pesquisa participativa é regularmente mobilizada na atualidade, correspondendo a uma longa tradição. No mundo todo, as metodologias participativas têm influenciado bastante nas escolhas metodológicas para lidar com necessárias mudanças sustentáveis em contextos educacionais ${ }^{(1)}$. Notadamente, as pesquisas que enfatizam a participação estão em um movimento no qual se faz a pesquisa com as pessoas/participantes e não para ou pelas pessoas/participantes ${ }^{(1,2)}$.

Acredita-se que a participação é elemento crucial para o encontro, a partir do qual se torna possível a formação de parcerias genuínas que carregam em si potencial para que transformações aconteçam ${ }^{(3)}$. Assim, é uma proposta que caminha para perspectivas emancipatórias para perspectivas de normatização.

Por isso, por meio das parcerias, é possível a constituição de redes de colaboração. Essas redes normalmente compartilham interesses comuns sobre questões específicas ${ }^{(4)}$, visando encontrar abordagens que lidem de forma mais adequada com as complexidades destas questões ${ }^{(5)}$.

Neste caminho, percebe-se o quão importante é o papel do elemento participação nas metodologias participativas, sendo, portanto, necessárias reflexões sobre seu conceito, sua operacionalização, suas características para que apoiem processos investigativos que usam esse tipo de metodologia. Cabe aqui destacar, também, que essa perspectiva metodológica de pesquisa tem potencialidade no âmbito do processo de consolidação do Sistema Único de Saúde (SUS).

A própria história de lutas e conquistas para a construção do SUS se pauta em um processo árduo de participações e posicionamentos ético-políticos, em que a sociedade civil, trabalhadores e gestores da saúde se organizaram para defenderem a proposta de criação do SUS nos espaços de discussão e de tomada de decisões. Dessa forma, a participação para a elaboração/processo de implantação do SUS e para materializar seus princípios revela a importância social de se colocar cada vez mais este assunto em pauta, acreditando-se no potencial das pesquisas com metodologias participativas para contribuírem no avanço destas discussões e na construção de espaços democráticos de tomada de decisão, o que é essencial para a consolidação do SUS baseado na concepção ampliada de saúde ${ }^{\left({ }^{(}\right)}$.

As metodologias participativas podem contribuir para produzir significado e sentido no campo da saúde. Enquanto produção social, cuja determinação é complexa e multifatorial, o campo da saúde, no Brasil, requer a participação ativa de usuários, movimentos sociais, profissionais e gestores da saúde e de outros setores implicados em sua produção, avaliação e formulação de ações vislumbrando melhor qualidade de vida( ${ }^{(7)}$. Isso é possível, por exemplo, por meio da participação nos Conselhos Locais de Saúde em suas reuniões periódicas e também nas Conferências de Saúde que acontecem a cada quatro anos, baseadas em princípios democráticos de participação(" ${ }^{(8)}$. Entretanto, o estudo mostra que há várias maneiras da participação ter sido entendida e praticada, com espaços de decisão pouco frutíferos para participações realmente de livre expressão e significativas para a vida dos sujeitos ${ }^{(9)}$.

Portanto, na área da saúde no Brasil, atividades que apoiem a construção de participação cada vez mais efetiva podem se mostrar como importantes dispositivos para ajudar na consolidação do SUS, especialmente em tempos de desconstrução desse sistema.

\section{Participação, colaboração, pesquisa-ação: de que se fala?}

Existe na América Latina e na Europa (regiões do mundo às quais pertencem os autores do presente artigo), por vezes, uma forte tradição e uma importante atualidade dos dispositivos de pesquisa que implicam uma dimensão participativa. Pensa-se, notadamente, na obra de Orlando Fals Borda ${ }^{(10-13)}$ sobre a pesquisa-ação participativa, nos dispositivos operacionalizados por Paulo Freire, visando à produção de conhecimentos pelos cidadãos sem-terra, e à longa tradição da pesquisa-ação colaborativa no campo da educação inaugurada pelo Instituto Nacional de Pesquisa Pedagógica, principalmente, nos anos de $1980^{(13)}$ e à tradição da Análise Institucional ${ }^{(14)}$.

Pesquisa-ação e participação não são, portanto, sinônimos. Geralmente, se associa o nascimento da pesquisaação às experiências lideradas por Kurt Lewin ${ }^{(15,16)}$ no quadro de seu projeto de "psicologia dinâmica". Vê-se aparecer nesse contexto as premissas de uma "teoria do engajamento" na qual a visão de participação é reduzida: trata-se de, em certos casos, de levar os sujeitos engajados na pesquisa a adotar os comportamentos esperados pelo pesquisador e, se a dimensão transformadora está presente, as preocupações éticas e políticas estão muito longe daquelas que se encontram no projeto de Fals Borda, por exemplo. Por "pesquisa-ação", é preciso compreender como um dispositivo que suponha a concepção, a operacionalização e a avaliação dos efeitos de um dispositivo 
(pedagógico, por exemplo). Em certos casos, os profissionais são simples agentes que operacionalizam um dispositivo pensado por eles mesmos, ou por outros (os pesquisadores) ${ }^{(17)}$. Da mesma maneira, existem alguns dispositivos de ciência "participativa" que dão muito espaço aos cidadãos (é a lógica dos projetos associados a um ideal da ciência cidadã) e que não se apoiam sobre a pesquisa-ação.

Os níveis de investimento dos atores, profissionais ou usuários, nos dispositivos de pesquisa participativa são, então, muito variáveis. Eles podem, em alguns casos, serem pontualmente consultados, ou mesmo estarem associados plenamente em todas as etapas da pesquisa: análise da situação, escolha da questão, coleta de dados, análise e interpretação, divulgação dos resultados da pesquisa. Além disso, a pesquisa participativa suscita um conjunto de questionamentos e que nem todos são necessariamente colocados (isso depende dos tipos de dispositivos considerados): questões éticas, referentes ao lugar do pesquisador e o dos sujeitos; questões políticas, ligadas à função social do pesquisador e ao poder que ele reconhece ao sujeito; questões epistemológicas, concernente ao estatuto, o valor, a legitimidade dos conhecimentos produzidos desde e com o cenário; questões metodológicas, relativas às condições de produção de saberes em um contexto participativo(17).

Assim, se as noções de pesquisa-ação e métodos participativos não se sobrepõem, e se não devemos imaginar uma unidade de pesquisa como uma dimensão participativa, escolhemos aqui focar em uma abordagem específica: a implementação de pesquisas participativas, mais especificamente em uma lógica de pesquisa-ação.

Nessa direção, este artigo continua aprimorando reflexões iniciadas anteriormente em um artigo ${ }^{(18)}$ que foi publicado nos anais do $6^{\circ}$ Congresso Ibero-Americano de Investigação Qualitativa que aconteceu em Portugal em julho de 2017. Assim, este artigo sobre a participação em pesquisas com metodologias participativas busca provocar reflexões acerca da participação, tomando como base algumas experiências de pesquisa com metodologia participativa.

\section{SÍNTESE DOS DADOS}

Trata-se de uma reflexão crítica sobre o elemento participação referente a experiências de pesquisa com uso de metodologia participativa, com destaque para a pesquisa-ação.

Para se conseguir explorar esta experiência de forma crítica, se faz necessário, primeiramente, chegar ao sentido que se quer atribuir ao termo experiência e, a partir daí, estabelecer como o saber de experiência ou da experiência vivida poderá ter significado para a construção de conhecimentos referentes ao uso de metodologias participativas de pesquisas.

Nesta direção, partilhar-se-á da reflexão de Bondía(19) sobre o termo 'experiência'. Para o autor, a experiência é aquilo que toca cada indivíduo, que não existe fora do mesmo, sendo, portanto, diferente dos termos 'informação', 'opinião'. Experiência é, nesse sentido o seguinte:

"a possibilidade de que algo nos aconteça ou nos toque [...] requer parar para pensar, parar para olhar, parar para escutar, pensar mais devagar, olhar mais devagar, e escutar mais devagar; parar para sentir, sentir mais devagar, demorar-se nos detalhes, suspender a opinião, suspender o juizo, suspender a vontade, suspender o automatismo da ação, cultivar a atenção e a delicadeza, abrir os olhos e ouvidos, falar sobre o que nos acontece, aprender a lentidão, escutar aos outros, cultivar a arte do encontro, calar muito, ter paciência e darse tempo e espaço" (p.24)

Assim, o sujeito da experiência é aquele da ação, a quem algo acontece ${ }^{(19,20)}$. Este pensamento, certamente, apoia as reflexões que se estabeleceram referentes às experiências vividas com o uso de metodologias participativas de pesquisa.

As pesquisas com metodologias participativas, portanto, pressupõem estudos que têm como critério de rigor metodológico que os participantes da pesquisa se coloquem cada vez mais envolvidos com a pesquisa (se exponham mais), em suas fases ao longo de todo percurso metodológico. Segundo Dick ${ }^{(21)}$, a participação pode ocorrer de formas distintas e em diferentes momentos da pesquisa, cabendo ao responsável pela pesquisa, juntamente com os participantes, decidirem como, quanto, quando os participantes atuarão.

As pesquisas a partir das quais esta reflexão se organiza tiveram abordagem qualitativa e técnicas de coleta de dados tais como observação participante, entrevista ${ }^{(22)}$, análise documental, encontros, oficinas, entrevistas convergentes ${ }^{(23)}$, dentre outros modos de trabalho. Estas técnicas de coleta de dados foram afinadas para pesquisas com metodologias participativas (mais especificamente a pesquisa-ação), seguindo alguns critérios de rigor, tais 
como: natureza cíclica, triangulação, criação de um clima para uma investigação flexível, apoio na literatura, monitoramento da mudança e avaliação(23).

Quanto ao período de coleta e análise de dados, houve variação de tempo de cinco meses a trinta e seis meses, entre 2014 e 2017. O número de participantes variou de 13 a 14 indivíduos. O principal referencial de análise de dados foi a proposta de Dick ${ }^{(23)}$ de confirmação e desconfirmação de dados em pesquisa-ação, baseado na perspectiva do processo dialético.

As etapas para a composição desta reflexão crítica foram as seguintes: 1-) seleção de características significativas na experiência/vivência durante pesquisas com metodologias participativas 2-) apresentação e discussão das características selecionadas; e 3-) apresentação de apontamentos relevantes.

\section{Discutindo Alguns Aspectos Essenciais da Participação em Pesquisas com Metodologias Participativas}

Para composição desta reflexão sobre as experiências, foram consideradas características significativas a partir das vivências em pesquisas com metodologias participativas, tais como a questão da participação enquanto processo (níveis de participação ao longo do processo investigativo); a flexibilidade no uso de técnicas de coleta de dados, ponto-chave na construção do processo participativo; e os ciclos: novos participantes, novas formas de participação.

\section{A Questão da Participação enquanto Processo (Níveis de Participação ao Longo do Processo Investigativo)}

A questão da participação em pesquisas com metodologias chamadas participativas é algo a que os pesquisadores despendem a maior parte da atenção ao longo do processo investigativo e também algo que demanda muita energia. Em experiências prévias relacionadas com a participação, conseguiu-se perceber pelo menos três características da participação: a participação enquanto processo gradual, a participação enquanto disponibilidade (tomada de decisão e assunção de papéis), a participação enquanto identificação (com o objeto de pesquisa, com o grupo de participantes, com os pesquisadores). Acredita-se que estas características sejam parte de um uno complexo que vai se formando ao longo do processo investigativo.

Percebe-se a participação enquanto processo, porque ela não ocorre a priori, ou seja, ela não é definida definitivamente antes do começo da pesquisa, ela é processual, construída gradualmente ao longo da investigação, conforme pesquisadores e participantes vão se apropriando de elementos que lhes permita tomar iniciativas, ocupar espaços, se colocar e se posicionar diante das situações de forma mais tranquila, transparente e livre de rechaças e retaliações. Nesse sentido, pode-se dizer que a participação que os indivíduos fazem em cada pesquisa, inclusive em cada momento da pesquisa, é única, singular e específica, ou seja, para cada pesquisa haverá uma construção de uma participação específica e esta participação vai se conformando ao longo do processo, sendo irregular, disforme, com intensidades diferentes de inserção, disponibilidade e engajamento das pessoas que estão na pesquisa (pesquisadores e pesquisandos).

A questão da participação enquanto disponibilidade/disposição pode trazer em si um rol de elementos referidos à tomada de decisões e assunção de papéis no processo investigativo: capacidade crítica e reflexiva para perceber o contexto, as outras pessoas e a pessoa se perceber no processo investigativo como ator; perceber a possibilidade real de participação, encontrando as formas individuais de participação e de contribuição; disponibilidade de tempo e de recursos necessários para participação, explorando suas potencialidades individuais para dedicá-las à construção dos percursos metodológicos da pesquisa em conjunto com outras pessoas concernentes.

A participação pode estar relacionada, também, a um movimento de identificação com o objeto de pesquisa, com o grupo participante, com o(s) pesquisador(es). Identificar-se com algo pode se referir a um movimento de olhar para si e encontrar similaridades com aquilo que nos é apresentado pelo contexto, seus atores e seus processos.

Todas estas três possíveis características indissociáveis da participação podem permitir a composição da característica individual, grupal e contextual de cada pesquisa - a unicidade e especificidade da pesquisa, a partir de que se podem extrair novas ideias e perspectivas investigativas para novos contextos.

A partir desses três aspectos, sugere-se que a participação vai se constituindo, com a sua diversidade de características e especificidades do momento, enquanto processo ao longo do desenvolvimento metodológico da pesquisa e não como um tipo de pré-requisito para se iniciar a pesquisa em si.

O papel dos pesquisadores, em um contexto de pesquisa participativa é então múltiplo. Essa pessoa (e, mais frequentemente, o coletivo de pesquisadores) deve, por vezes, acompanhar os sujeitos engajados na pesquisa, Ihes oferecer algumas ferramentas para elaborar e conduzir sua própria pesquisa com uma grande liberdade, mas também propor e, às vezes, até mesmo fundamentar, um quadro que permita colocar em marcha uma abordagem científica. 
Nessa direção, é essencial a criação de um clima favorável por meio de uma investigação aberta, valorizando desde o início da pesquisa o momento de entrada e o contrato, os quais buscam construir relações abertas, em que o pesquisador possa ser ao mesmo tempo confrontador e apoiador nas discussões junto aos participantes. Trata-se de se construir um engajamento real a partir da verdadeira essência de cada pessoa ${ }^{(23,24)}$.

Destacam-se, ainda, algumas outras características na questão da entrada e contrato, segundo Dick, que são as seguintes, nomeadamente o rapport:

- rapport e relacionamento: rapport é um estado de interação em que "as pessoas estão em sintonia". Nesse sentido, o autor sugere que o pesquisador, ao buscar o envolvimento do participante, deverá demonstrar interesse genuíno no ponto de vista do outro, buscando estabelecer rapport e um relacionamento pessoa a pessoa de alta qualidade com cada participante, para minimizar outras questões que possam surgir ao longo do percurso investigativo ${ }^{(23)}$.

- negociar papéis: buscar quem vai se envolver na pesquisa, qual o nível de envolvimento sendo importante defini-lo com os participantes, que restrições de operacionalização da pesquisa ou quanta flexibilidade haverá(23).

Com base nessas considerações, no processo de participação, ao longo do decorrer da pesquisa é esperado que a participação ou o nível de participação varie progressivamente.

\section{A Flexibilidade no Uso de Técnicas de Coleta de Dados: Ponto-chave na Construção do Processo Participativo}

Compreende-se a flexibilidade como uma característica que permite aos processos investigativos e suas condições pré-estabelecidas ressignificarem-se diante do imprevisto, do inédito, com vistas à construção de novas e específicas estratégias que permitirão a coleta dos dados adequadamente realizada.

A flexibilidade no uso de variadas técnicas de coleta e análise de dados pode permitir que a disponibilidade e a disposição, referidas no item anterior, se coloquem como um processo em construção ao longo da participação na pesquisa, permitindo que peculiaridades individuais, grupais, contextuais não se configurem como barreira ao processo participativo, mas como situações-limites que disparam novas formas, estratégias e técnicas de coletas e análise de dados flexíveis e, portanto, contextualizadas e, também, singularizadas. Considerar o contexto e as singularidades constrói um ambiente mais agradável, revela empatia e traz segurança, tornando-se o dinamismo coerente e adequado às peculiaridades que emergiram, possibilitando a continuidade da investigação.

Assim, a flexibilidade se configura como um critério de rigor, tornando-se fundamental nas pesquisas que assumem metodologias participativas para desenvolver um processo investigativo.

A capacidade criativa e dialógica pode ser, então, um componente crucial aos processos participativos de pesquisa, o que pode favorecer um maior grau de comprometimento e interação dos participantes. Se mudança e compreensão são propósitos almejados na pesquisa, impreterivelmente há de se ter muita interação.

Para o processo de mudança, alguns componentes cruciais devem ser considerados, nomeadamente os seguintes: entrada e contrato; diagnóstico; intervenção; e saída ${ }^{(21)}$. No componente entrada e contrato, o autor refere a importância da entrada e conhecimento do campo e dos atores, com negociação dos papéis de todos os envolvidos. O diagnóstico é realizado com a participação de todos os envolvidos para identificar o que precisa de mudança. A partir do diagnóstico, é possível planejar ações a serem implementadas. Por fim, organiza-se a saída de campo e o fechamento do trabalho para aquele momento. Apesar de não ter aparecido avaliação entre os componentes referidos, o autor ressalta que prefere fazer a avaliação a todo o momento ao longo da pesquisa, como integrante do binômio ação-reflexão. Segundo o autor, a flexibilidade é componente crucial do modelo espiral de pesquisaação, por exemplo, quando juntos são os responsáveis pela responsividade às transformações ${ }^{(21)}$. Assim, todos esses componentes apresentados se sobrepõem, a todo o momento, de forma dinâmica e cíclica configurando a natureza cíclica da pesquisa, item a ser discutido a seguir.

Enquanto alguns defendem a flexibilidade como um critério de rigor nas pesquisas participantes, o fato de usar variados métodos para coleta de dados compactuados entre participantes e pesquisadores, outros referem que a abordagem flexível ainda é considerada como de menor rigor científico, necessidade de padronizações, entre outras considerações, talvez por se avaliarem as metodologias participativas a partir de critérios advindos de outras perspectivas epistemológicas ${ }^{(23,25-27)}$.

\section{Os Ciclos: Novos Participantes, Novas Formas de Participação}

Pode-se entender os ciclos como etapas completas de um todo, mas que se completam a partir das etapas anteriores e que são essenciais para disparar as etapas seguintes. Pode-se contemplar os ciclos como cada volta 
de um processo espiral contínuo, em que se volta às situações vividas, aos momentos compartilhados, dentre outros fatores, sempre com um grau complexidade maior. Em suma, os ciclos são a melhor escolha de delineamento para responder às questões complexas e incertas, conferindo grande flexibilidade ao processo investigativo(23,24).

Os ciclos podem permitir olhar-se mais uma vez para a experiência vivida, para as informações e dados coletados, analisados e interpretados, adentrando mais profundamente no universo das significações, aprofundando nos sentidos e significados. Os ciclos podem permitir também o compartilhamento de interpretações, de significados e de sentidos, para sensos e consensos cada vez mais representativos das coletividades.

A organização da pesquisa em ciclos (por exemplo, as pesquisas participativas) pode oferecer aos participantes novas oportunidades de aprofundamento no movimento de participação, renovando, reconfigurando e ressignificando, a cada ciclo, a disponibilidade, a disposição e as identificações que cada participante tenha trazido consigo e com os outros, ou seja, é como se fosse considerado um metaprocesso de pesquisa ${ }^{(23)}$. Essa participação pode ir se conformando ao longo do processo investigativo, por meio da construção de rapport, em que a partir do encontro de pessoas e suas singulares possibilidades comunicativas (visual, gesto, fala, escuta, dentre outros fatores), se promove uma espécie de contexto comunicativo intra e interpessoal. Acredita-se que seja nesse contexto que é mais possível negociar expectativas, definir papéis, traçar metas, tomar decisões quanto à participação na pesquisa, construindo parcerias genuínas para o sucesso da investigação.

Nossa experiência mostrou que, ao longo dos ciclos e dos diversos ciclos que acontecem dentro de cada ciclo (nested cycles) ${ }^{(28)}$, os encontros são ressignificados. S exercita a fala, a escuta, a abertura e o respeito com o tempo de encontro.

O contexto e as diferenças de cada um são aspectos essenciais para a construção do vínculo, ressignificando também os participantes e a forma de participação. Esses aspectos, ao longo dos ciclos e ao longo do tempo favorecem a participação, mas mais do que isso, esses aspectos, na nossa vivência, foram a gênese para o nascimento de uma parceria realmente genuína, a qual pode ser observada e vivenciada até os dias de hoje, passados três anos do início do primeiro ciclo. Considerando a natureza cíclica dos processo de transformação e, portanto, a continuidade, a parceria genuína alcançada é uma ferramenta potente para alcance de transformações e resultados. Neste ponto, a título de exemplificação, referimo-nos a uma pesquisa-ação realizada com trabalhadores do Sistema Único de Saúde (SUS) que buscavam caminhos para a consolidação de práticas integrativas e complementares (PIC), nos serviços de saúde da localidade onde residiam. Assim, por meio da pesquisa-ação e da construção de vínculo (rapport), percebeu-se o fortalecimento das ações e das iniciativas para ajudar a alavancar processos que visam a consolidação das PICs nos serviços locais de saúde do SUS.

A interlocução junto aos participantes, a abordagem individualizada e o convite para participar do trabalho/da pesquisa, explicitando os papéis dos participantes enquanto parceiros e coautores, isso interfere diretamente no engajamento e compromisso destes no processo investigativo - a parceria é algo que também é construído em processo, vai muito além do encontro de pessoas, precisando de tempo para criar condições para que ela emirja ${ }^{(29,30)}$. Quanto mais o participante buscar desenvolver a parceria e a coautoria, mais ativo e participativo este será. Essa participação é essencial nessa modalidade de pesquisa, de modo que não é possível haver sujeitos passivos ou posturas não participativas nesse processo. Cada um, ao seu modo, tem algum tipo de participação. O importante é deixar explícito como a participação e sua transformação foram ocorrendo ao longo do processo investigativo quem participou de cada momento, como participou, o que contribuiu, evitando entender a participação a partir de perspectivas generalizadoras, como se fosse algo simétrico, equilibrado e estável.

Com a finalidade de ilustrar esta discussão, apresenta-se um esquema representacional da participação ao longo de pesquisas com delineamentos participativos. Buscou-se essa construção afastando-se o máximo possível de ideias de linearidade, de simetria, de retidão no traço, fazendo ao mesmo tempo uma representação do movimento de participação com seus nuances, suas tortuosidades, suas assimetrias, pensando em ciclos assimétricos, apenas preservando a ideia de continuidade que se faz presente nesse processo de construção da participação. Destaca-se também, os contornos únicos e singulares de cada ciclo, de cada momento, de cada participação, ou seja, cada ciclo, cada momento, cada participação não são como os antecedentes ou mesmo não serão como os descendentes.

O planejamento na pesquisa continua durante e também ao longo de todo o processo investigativo, buscando na participação e no envolvimento dos indivíduos a legitimação para a construção de conhecimentos significativos e contextualizados. Conforme se caminha no processo dos diversos momentos da pesquisa, a construção de relações interpessoais, de confiança, de compromisso podem potencializar e intensificar a participação(23). 


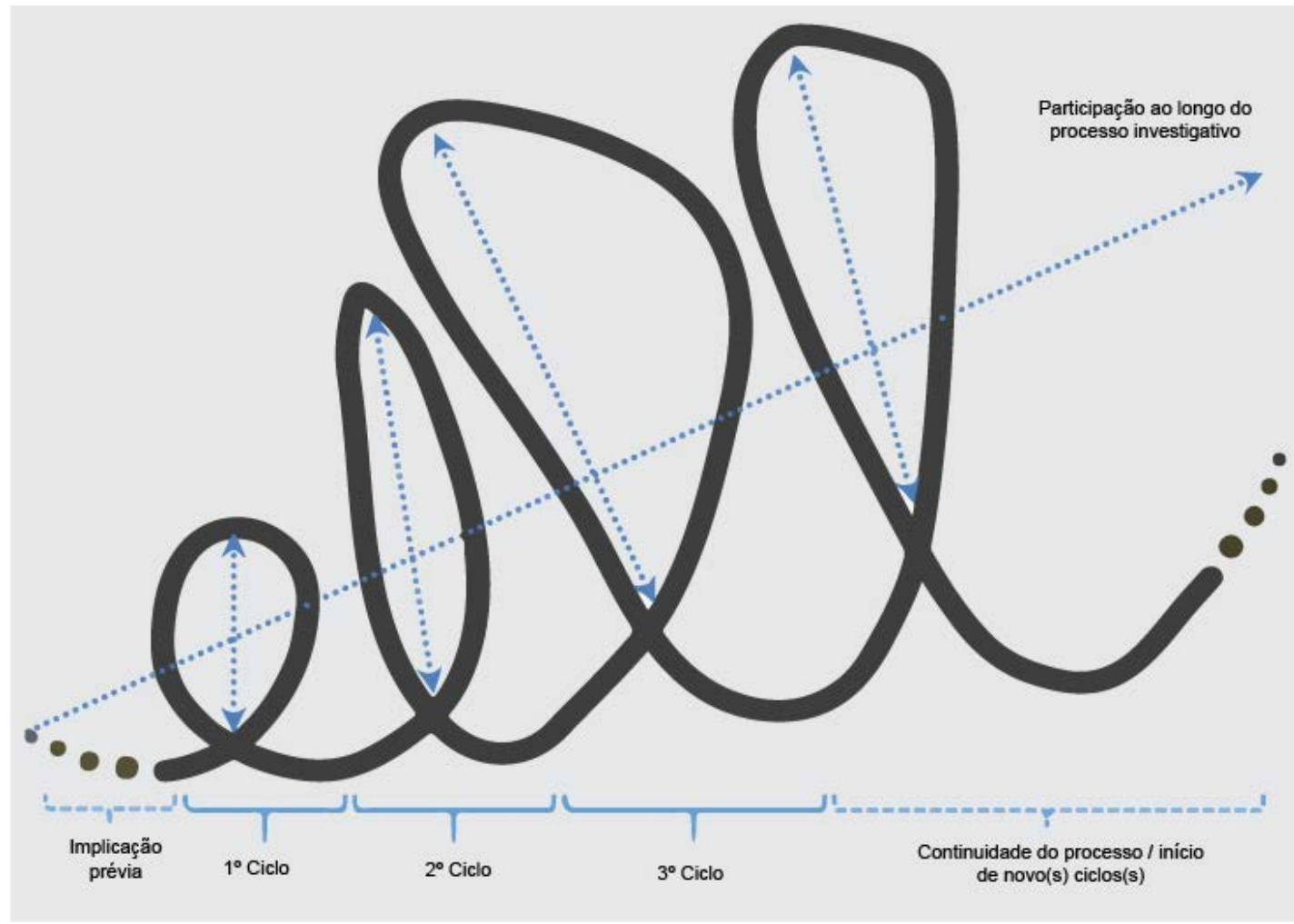

Fig. 1 - Representação da participação ao longo dos ciclos de uma pesquisa participativa. Fonte: construção dos autores.

Foi bastante recorrente a variação de participação tanto em número como em grau de participação. Ao longo de todo o processo investigativo, houve decréscimos e acréscimos - desistências e novas participações. Quanto às desistências, é possível refletir que ora as experiências de participar nas pesquisas deixaram de tocar algumas pessoas, ora outros elementos atravessaram o caminho dos indivíduos, dificultando ou impedindo suas participações, sem que houvesse flexíveis possibilidades outras de assegurar a participação por meio de outros caminhos metodológicos. Em contrapartida, novas participações puderam surgir em novos ciclos da investigação, reforçando e ampliando os olhares sobre um processo ou uma experiência já em andamento, já com alguma construção em andamento.

A título de exemplo de outra maneira de participação, apoiada na perspectiva da pesquisa socioclínica( ${ }^{(31)}$, destaca um dispositivo bastante interessante utilizado para ampliação, em que se busca o envolvimento de outras pessoas pertinentes à pesquisa, mas que não tinham sido identificadas ou percebidas como tal em momentos anteriores da pesquisa. Assim, provoca-se uma ressignificação da participação na pesquisa, em que novos participantes essenciais vão surgindo e sendo indicados ao longo do processo, os quais também vão causando outros efeitos sobre a participação desenvolvida até então.

$\mathrm{Na}$ nossa experiência, vivenciamos o enriquecimento do trabalho quando outras pessoas com diferentes inserções na rede de assistência à saúde (gestores, trabalhadores etc.) começaram a participar das oficinas, das discussões, contribuindo significativamente para o alcance dos objetivos propostos. Essa ampliação se deu a partir das necessidades levantadas ao longo dos primeiros momentos da pesquisa-ação (nos primeiros ciclos), a partir de objetivos que, para serem alcançados, outras pessoas com inserção política e poder de decisão diferentes eram cruciais para o seu encaminhamento.

\section{Uma Reflexão sobre os procedimentos em Comitês de Ética em Pesquisa com Seres Humanos}

As pesquisas que envolvem seres humanos devem seguir alguns acordos e preceitos estabelecidos, por exemplo, na Declaração de Helsinki identificados e em outros documentos específicos de cada país.

Neste sentido, como as metodologias participativas expressam a relevância da participação de pessoas em contextos investigativos, é de suma importância o acompanhamento contínuo por comitês de pesquisa. Entretanto, o processo pode ficar um tanto moroso e precisa ser minuciosamente acompanhado, especialmente quando se trata de pesquisas para o efeito de escritas de teses, em que há prazos pré-estabelecidos para início e término (encomendas atuais dos estabelecimentos formativos). 
Algumas características a serem destacadas quanto à passagem por avaliação de comitês de ética em pesquisa com seres humanos se referem, principalmente, à natureza epistemológica de metodologias participativas. No presente caso da pesquisa-ação, tais pressuposições implicam flexibilidade e ciclos de trabalho, ambos os condicionantes intrinsecamente relacionados entre si e com a participação.

No que se refere à natureza flexível da pesquisa-ação, ao longo do seu processo investigativo é possível que haja a necessidade de criar ou reinventar, em conjunto com os participantes, alternativas à forma de participação, à forma de coleta de dados e à forma de análise dos dados. Essa característica das pesquisas com metodologias participativas requer modificações constantes no processo investigativo, o que precisa estar claro para os comitês de ética. Cada ajuste que altere o percurso metodológico da pesquisa será motivo de nova consulta ou comunicação ao comitê de ética. Donde, o desafio seja desenvolver escritas metodológicas que traduzam ou indiquem esta transformação permanente por que passam pesquisas com metodologias participativas. Certos exemplos por nós vivenciados se referem a modificações de passos nos momentos de coleta de dados, nos tipos de encontro, nas formas esperadas de participação (participação desde o início, a partir do segundo ciclo, apenas em "rodas de discussão", apenas em momentos exploratórios, etc.). Neste sentido, é preciso prever a possibilidade de que ao longo do percurso metodológico apareçam novos participantes, que contribuirão de inúmeras maneiras à pesquisa, ao grupo de participantes em si.

A depender dos procedimentos de cada comitê de ética, se coloca o tempo de envio e recebimento de aprovações, correções, explicações, podendo variar muito, assim como os prazos fixados para comunicações com os comitês de ética. Por esses condicionantes, é preciso o acompanhamento atento aos prazos durante o planejamento prévio da investigação científica, especialmente em pesquisas que visam à produção de dissertações e teses, e que tenham uma encomenda pré-estabelecida pelos estabelecimentos formativos.

\section{CONCLUSÃO}

Para finalizar essa reflexão, cabe ressaltar a especificidade epistemológica das metodologias participativas, neste caso, da pesquisa-ação, dada a sua natureza de evidenciar a provisoriedade do conhecimento, o qual se tece contextualmente em um processo de construção coletiva, resguardando a singularidade e a unicidade de cada momento, contexto e indivíduo participante.

Apresentamos a participação como um processo construído individual e coletivamente e, assim, também é um processo de aprendizagem sobre os mecanismos de pesquisas com metodologias participativas. Poder-se-ia dizer que se trata de um trabalho artístico de construção, em que as pessoas e os processos vão se tecendo e se ressignificando ao longo da investigação. Desse modo, tudo se refere a um processo de transformação: transformação do contexto, dos participantes, dos pesquisadores, do processo investigativo, das realidades, entre outras circunstâncias. Acredita-se que é nesse processo de transformação que se pode proceder ao conhecimento.

Por isso, a mudança ou a transformação, típica de pesquisas com metodologias participativas, tem como condição sine qua non a flexibilidade e a participação, para permitir que o processo de conhecimento transcorra de forma contextualizada em meio à complexidade da existência humana.

A produção científica pode ser operacionalizada nos cotidianos, no campo da saúde e no campo da educação, de modo a diminuir a distância existente entre o que é produzido pela comunidade científica e a incorporação dessa produção científica no cotidiano do exercício profissional. Consideramos o desenvolvimento de mais estudos de natureza qualitativa e participativa como um caminho profícuo nessa direção.

Portanto, pesquisas com metodologias participativas podem ser potentes para apoiar movimentos de consolidação de propostas também elaboradas de maneira participativa, tal como a construção do Sistema Único de Saúde (SUS).

\section{AGRADECIMENTOS}

Agradecemos ao Professor Dr. Bob Dick pelo curso de Pesquisa-ação, por meio do Programa AREOL (Action Research and Evaluation Online - Web). Agradecemos ao CNPq e à CAPES pelo financiamento de pesquisas de doutoramento, pós-doutoramento e estágio de doutorado-sanduíche (PDSE-CAPES) que possibilitaram essas reflexões.

\section{CONFLITOS DE INTERESSE}

Não houve conflito de interesse. 


\section{REFERÊNCIAS}

1. Bergold J, Thomas S. Participatory Research Methods: A Methodological Approach in Motion. Forum: Qualitative Social Research [periódico na Internet]. 2012 [acesso em 2017 Dez 5]; 13(1). Disponível em: http://www. qualitative-research.net/index.php/fqs/article/view/1801/3334.

2. Monceau G, Soulière $M$. Mener la recherche avec les sujets concernés: comment et pour quels résultats? . Éducation et socialisation Les Cahiers du CERFEE [periódico na Internet]. 2017 [acesso em 2017 Dez 5]. Disponível em: http://journals.openedition.org/edso/2525

3. Edwards-Groves C, Brennan Kemmis R, Hardy I, Ponte P. Relational architectures: recovering solidarity and agency as living practices in education. Pedagogy, Culture \& Society [periódico na Internet]. 2010 [acesso em 2017 Dez 5];18(1):43-54. Disponível em : https://doi.org/10.1080/14681360903556814

4. Bowie JE, Werhane PH. Management Ethics. Malden, MA: Wiley-Blackwell; 2004.

5. Roloff J. Learning from Multi-Stakeholder Networks: Issue-Focussed Stakeholder Management [periódico na Internet]. Journal of Business Ethics. 2008 [acesso em 2017 Dez 5];82(1):233-50. Disponível em: https://link. springer.com/article/10.1007/s10551-007-9573-3

6. Coelho JS. Construindo a participação social no SUS: um constante repensar em busca de equidade e transformação. Saúde e Sociedade [periódico na Internet]. 2012 [acesso em 2017 Dez 5];21: 138-51. Disponível em: http://dx.doi.org/10.1590/S0104-12902012000500012

7. Rocha PR, David HMSL. Determination or determinants? A debate based on the Theory on the Social Production of Health. Revista da Escola de Enfermagem da USP [periódico na Internet]. 2015 [acesso em 2017 Dez 5];49: 129-35. Disponível em: http://dx.doi.org/10.1590/S0080-623420150000100017

8. Rolim LB, Cruz RSBLC, Sampaio KJAJ. Participação popular e o controle social como diretriz do SUS: uma revisão narrativa. Saúde em Debate [periódico na Internet]. 2013 [acesso em 2017 Dez 5];37:139-47. Disponível em: http://dx.doi.org/10.1590/S0103-11042013000100016

9. Costa DFC, Paulon SM. Participação Social e protagonismo em saúde mental: a insurgência de um coletivo. Saúde em Debate [periódico na Internet]. 2012 [acesso em 2017 Dez 5];36:572-82. Disponível em: http://dx.doi. org/10.1590/S0103-11042012000400009

10. Fals Borda O. Investigación Participativa. Montevideo: La Banda Oriental; 1987.

11. Brandão CR. Repensando a Pesquisa Participante. São Paulo, SP: Brasiliense; 1984.

12. Brandão CR. Pesquisa Participante. São Paulo, SP: Brasiliense; 1981.

13. Barbier R. La Recherche Action dans I'Institution Éducative. Paris, FR: Gauthier-Villars; 1977.

14. Lapassade G. Recherche-action externe et recherche-action interne. Pratiques de Formation-Analyses. 1989(18).

15. Lewin K, Lewin GW. Resolving social conflicts: selected papers on group dynamics. Nova York, EUA: Harper and Brothers; 1948.

16. Melo ASE, Maia Filho ON, Chaves HV. Lewin e a pesquisa-ação: gênese, aplicação e finalidade. Fractal: Revista de Psicologia [periódico na Internet]. 2016 [acesso em 2017 Dez 5];28:153-9. Disponível em: http://dx.doi. org/10.1590/1984-0292/1162

17. Banks S, Armstrong A, Carter K, Graham H, Hayward P, Henry A, et al. Everyday ethics in community-based participatory research. Contemporary Social Science [periódico na Internet]. 2013 [acesso em 2017 Dez 5];8(3):263-77. Disponível em: http://www.tandfonline.com/doi/pdf/10.1080/21582041.2013.769618

18. Gatto Júnior JR, Sousa LA, Pesce S, Fortuna CM. Reflexões Críticas sobre Participação em Pesquisas com Metodologias Participativas. In: $6^{\circ}$ Congresso Íbero-Americano de Investigação Qualitativa; 2017 Jul 12-14; Salamanca; 2017.

19. Bondía JL. Notas sobre a experiência e o saber de experiência. Revista Brasileira de Educação [periódico na Internet]. 2002 [acesso em 2017 Dez 5];(19):20-8. Disponível em: http://dx.doi.org/10.1590/S1413-24782002000100003

20. Bondía JL. Experiência e alteridade em Educação. Revista Reflexão e Ação [periódico na Internet]. 2011 [acesso em 2017 Dez 5];19(2):04-27. Disponível em: https://online.unisc.br/seer/index.php/reflex/article/view/2444/1898 
21. Dick B. Postgraduate programs using action research. The Learning Organization [periódico na Internet]. 2002 [acesso em 2017 Dez 5];9(4):159-70. Disponível em: https://doi.org/10.1108/09696470210428886

22. Minayo MCS, Zito Guerriero IC. Reflexividade como éthos da pesquisa qualitativa. Ciência \& Saúde Coletiva [periódico na Internet]. 2014 [acesso em 2017 Dez 5]; 19(4):1103-12. Disponível em: http://www.redalyc.org/ articulo.oa?id=63030543011

23. Dick B. Action research and evaluation online email-based course. Australia: Southern Cross University and the Southern Cross Institute of Action Research; 2002. Disponível em: http://www.aral.com.au/areol/areolind.html

24. Argyris C, Putman R, Smith DM. Action science: concepts, methods and skills for research and intervention. San Francisco, CA: Jossey-Bass; 1985.

25. Kristiansen M, Bloch-Poulsen J. Participação na Pesquisa-ação: entre a metodologia e a visão de mundo, participação e codeterminação. Trabalho \& Educação [periódico na Internet]. 2013 [acesso em 2017 Dez 5]; 22(1). Disponível em: https://seer.ufmg.br/index.php/trabedu/article/view/7502/5808

26. Kim J. Youth Involvement in Participatory Action Research (PAR): Challenges and Barriers. Critical Social Work [periódico na Internet]. 2016 [acesso em 2017 Dez 5]; 17(1). Disponível em: http://www1.uwindsor.ca/ criticalsocialwork/youth_involvement

27. Edwards-Groves C, Olin A, Karlberg-Granlund G. Partnership and recognition in action research: understanding the practices and practice architectures for participation and change. Educational Action Research [periódico na Internet]. 2016 [acesso em 2017 Dez 5];24(3):321-33. Disponível em: https://doi.org/10.1080/09650792.20 15.1129983

28. Dick B, Sankaran S, Shaw K, Kelly J, Soar J, Davies A, et al. Action research as metamethodology: managing the complexity of an applied research project. In: 14th European Academy of Management Conference (EURAM 2014): Waves and Winds of Strategic Leadership for Sustainable Competitiveness; 2014 Jun 4-7; Valencia, ES; 2014.

29. Kemmis S, McTaggart R, Nixon R. The action research planner: doing critical participatory action research. Singapore: Springer; 2014.

30. McAllister S. Developing home-school partnership: from concepts to practice. New York, NY: Teachers' College Press; 1993.

31. Monceau G. Técnicas socioclínicas para a análise institucional das práticas sociais. Psicologia em Revista [periódico na Internet]. 2015 [acesso em 2017 Dez 5];21:197-217. Disponível em: http://dx.doi.org/DOI-10.5752/ P.1678-9523.2015V21N1P197

\section{Endereço para correspondência:}

José Renato Gatto Júnior

Escola de Enfermagem de Ribeirão Preto

Av. dos Bandeirantes, 3900 - Campus Universitário

Bairro: Monte Alegre

CEP: 14040-902 - Ribeirão Preto - SP - Brasil

E-mail: jose.gatto@usp.br 